\title{
Measurement of abdominal wall compliance in normal subjects and tetraplegic patients
}

\author{
JM GOLDMAN, LS ROSE, MDL MORGAN, DM DENISON
}

From the Lung Function Unit, Brompton Hospital, London; and the National Spinal Injuries Centre, Stoke Mandeville Hospital, Aylesbury

ABSTRACT On inspiration descent of the diaphragm is opposed by the passive properties of the abdominal wall, the tone of its muscles, and the inertia of the abdominal contents. As a result, intra-abdominal pressure rises and promotes rib cage expansion. In patients with high spinal injury the diaphragm is the most important muscle of inspiration and abdominal wall displacement is more evident than in normal subjects. Abdominal wall compliance has been measured by relating gastric pressure to abdominal wall displacement, which was determined by means of an optical contour mapping system. Six normal subjects and six tetraplegic patients were studied in the supine posture, during passive expiration from total lung capacity to functional residual capacity. Over this lung volume range the normal subjects partitioned an average of $31 \%$ of expired volume to the abdominal compartment, while the corresponding average figure in the patients was $77 \%$ of expired volume. Since the range of gastric pressure was similar in the two groups, it is concluded that abdominal wall compliance is greater in tetraplegic patients. This high compliance could have a detrimental effect on lower rib cage expansion.

Many investigators have noted that the abdominal wall moves more during breathing in tetraplegic patients than in normal subjects. Bergofsky ${ }^{1}$ and Mortola and Sant Ambrogio ${ }^{2}$ have suggested that it does so because the rib cage is fixed or moves paradoxically. Danon et $^{3} \mathrm{l}^{3}$ suggested that paralysis and disuse atrophy of respiratory muscles may disturb the partitioning of compliance between rib cage and abdomen. This paper describes a study of the distensibility of the abdominal wall during a relaxed expiration from total lung capacity (TLC) to functional residual capacity (FRC) in normal subjects and patients with tetraplegia. It was conducted to test the idea that there would be easier abdominal wall displacement and therefore less resistance to descent of the diaphragm in tetraplegic patients than in healthy subjects. The gastric pressure/displaced volume characteristic of the anterolateral abdominal wall was used as a measure of distensibility.

Address for reprint requests: Dr JM Goldman, Lung Function Unit, Brompton Hospital, London SW3 6HP.

Accepted 9 December 1985

\section{Methods}

Six normal men age 19-35 (mean 27) years and six tetraplegic patients also aged 19-35 (mean 28) were examined (table). Five of the tetraplegic patients were men. All six had complete transection of the cervical spinal cord and none was suffering any respiratory complication at the time of examination. They were examined at least three months after injury, at which stage there was evidence of spasticity of the limbs. All subjects were studied supine.

Gastric pressure was measured with an oesophageal balloon $10 \mathrm{~cm}$ in length placed in the gastrointestinal tract $65 \mathrm{~cm}$ from the external nares. The balloon contained $1.5 \mathrm{ml}$ of air. Its subdiaphragmatic position was confirmed by observation of a positive pressure deflection when the subject

\section{Details of the patients}

\begin{tabular}{lllll}
\hline $\begin{array}{l}\text { Patient } \\
\text { No }\end{array}$ & $\begin{array}{l}\text { Age } \\
(y)\end{array}$ & Sex & $\begin{array}{l}\text { Level of } \\
\text { injury }\end{array}$ & $\begin{array}{l}\text { Time after } \\
\text { injury (w) }\end{array}$ \\
\hline 1 & 34 & F & C5 & 30 \\
2 & 21 & M & C5/6 & 27 \\
3 & 36 & M & C7 & 17 \\
4 & 24 & M & C6 & 17 \\
5 & 19 & M & C5 & 27 \\
6 & 33 & M & C5/6 & 39 \\
\hline
\end{tabular}




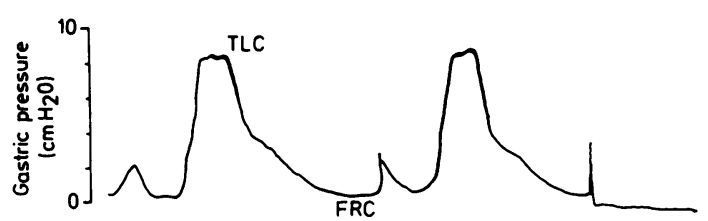

Camera

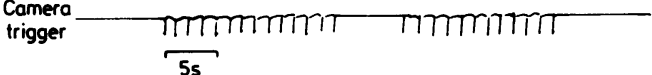

Fig 1 Typical gastric pressure record of a normal supine subject during passive expiration from total lung capacity (TLC) to functional residual capacity $(F R C)$, with the camera trigger marked.

sniffed. The balloon was connected to an Elema Schonander EMT 35 pressure transducer, linked via an amplifier to a Gould 4400 thermal pen recorder. The transducer was calibrated with a water manometer before and after each study. It remained linear within the range $\pm 0 \cdot 2 \mathrm{~cm} \mathrm{H}_{2} \mathrm{O}$ to $60 \mathrm{~cm} \mathrm{H}_{2} \mathrm{O}$.

Abdominal wall displacement was measured by an optical contour mapping technique designed for use in recumbent patients. ${ }^{4}$ Briefly, a pattern of horizontal stripes was projected on to either side of a supine subject and the resulting contour lines formed on the trunk were photographed from above with a $35 \mathrm{~mm}$ camera. Information about the shape and volume of the chest wall was retrieved by projecting the photograph on to a digital plotting table connected to a Prime-750 computer. This system defines the spatial coordinates of about 1000 points on the surface of the trunk. ${ }^{5}$ It can be used to separate the volume displacements of the rib cage and abdominal compartment if the lower costal margin is used as a boundary visible in each photograph. ${ }^{6}$ The camera was fired at a rate of one frame a second by an electrical trigger, which also marked the pressure record so that the photograph which corresponded to a given pressure could be determined.

Each subject was trained to expire passively through pursed lips from TLC to FRC over a period of eight to 10 seconds. Preliminary experiments showed that there was no electromyographic activity of their abdominal muscles during this manoeuvre. They were taught to recognise and avoid active expiration by an investigator who monitored gastric pressure. During the passive expiration gastric pressure was at its maximum at TLC and declined exponentially to a minimum at FRC (Fig 1). Expiratory abdominal muscle activity superimposed positive pressure pulses on this pattern. None of the traces used in the formal study showed such activity. Each subject was asked to perform 12 passive expirations. When the subject reached TLC, the cam- era was triggered to take photographs at one second intervals throughout the expiration. From the 12 pressure recordings a representative waveform was identified and the corresponding single set of photographs analysed to determine the gastric pressurevolume displacement characteristic of the abdominal compartment.

\section{Results}

Figure 2 shows a pressure-volume displacement (PV) curve typical of a normal abdomen. The change in slope of this curve reflects the compliance of the passive anterolateral abdominal wall at the various levels of distension through the manoeuvre. One such curve was constructed for each normal subject and each patient with tetraplegia. Figure 3 shows five replicate analyses of a set of photographs from a single manoeuvre in one patient. It also shows the least squares quadratic curve fitting the data and the standard error $(27 \mathrm{ml})$ of that estimate. Figure 4 shows five attempts by a normal subject to reproduce the passive expiration manoeuvre. The least square quadratic curve fitting these data had a standard error of the estimate of $37 \mathrm{ml}$.

All the pressure displaced volume curves obtained in this study were of similar shape. At low lung volumes, when intra-abdominal pressure is low, abdominal displaced volume rises rapidly and the abdominal wall is at its most compliant. At high lung volumes the rate of rise of abdominal displaced volume decreases, the curve of pressure against displaced vol-

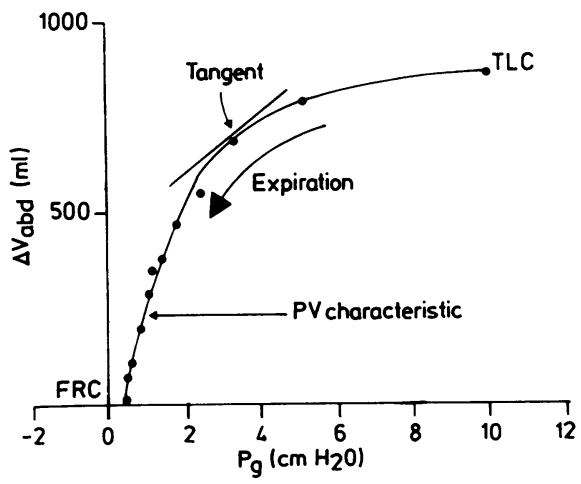

Fig 2 Gastric pressure-volume displacement characteristic of the abdominal wall of a normal supine subject ( $P V$ characteristic). At the point marked by the arrow the slope ofo the tangent measures abdominal wall compliance. $\mathrm{P}_{\mathrm{g}}-$ gastric pressure; $\triangle V_{a b d}$ volume displacement of the abdominal wal $\bar{D}$ above that at functional residual capacity (FRC); $T L C$-total lung capacity. 


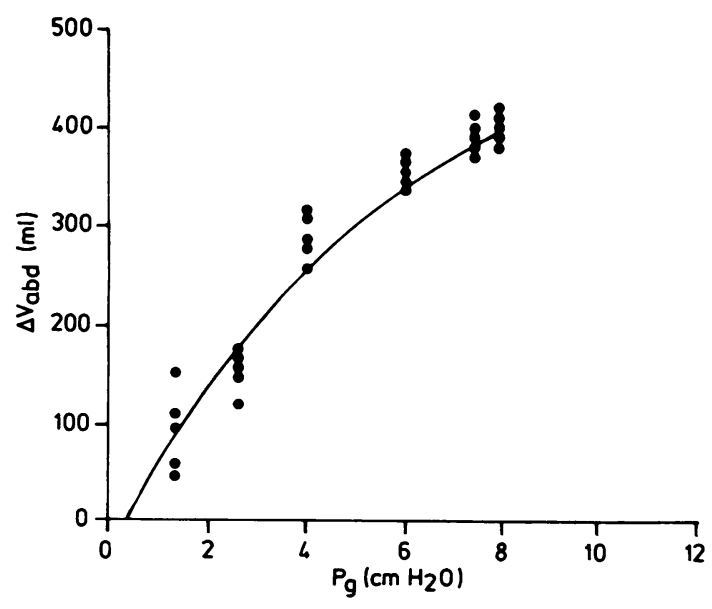

Fig 3 Reproducibility of the digitisation procedure: one manoeuvre digitised five times, with the quadratic curve of best fit (standard error of estimate $27 \mathrm{ml}$ ). $P_{\mathrm{g}}-$ gastric pressure; $\triangle V_{\text {abd-volume displacement of the abdominal wall }}$ above that at functional residual capacity.

ume flattens off, and abdominal wall compliance is diminished. Figure $5 a$ shows single curves typical of each of the six normal subjects. Gastric pressure is plotted against the absolute volume displacement of the anterolateral abdominal wall. The range of gastric

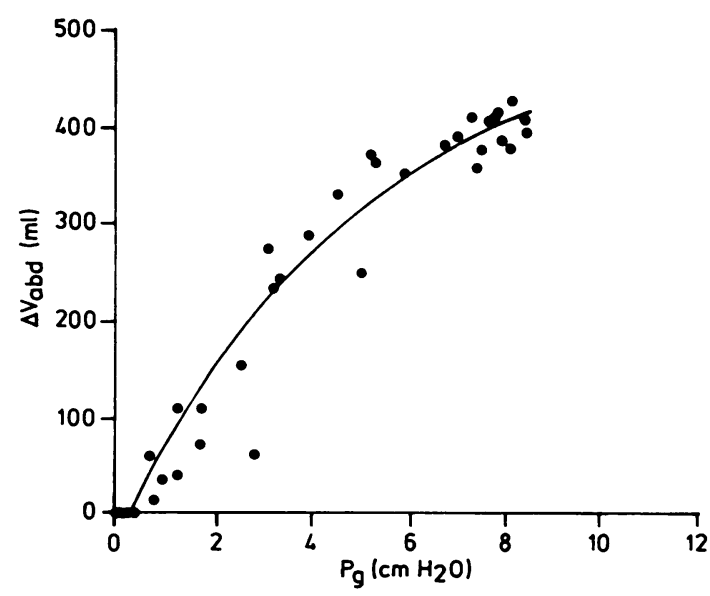

Fig 4 Reproducibility of the passive expiration manoeuvre. Five manoeuvres from one normal subject, with the quadratic curve of best fit (standard error of estimate $37 \mathrm{ml}$ ).

$P_{\mathrm{g}} \rightarrow$ gastric pressure; $\triangle V_{\text {abd }}$-volume displacement of the abdominal wall above that at functional residual capacity.

pressure measured in supine normal subjects was from -0.5 to $+11.4 \mathrm{~cm} \mathrm{H}_{2} \mathrm{O}$ during a relaxed expiration. At TLC gastric pressure was in the range $+9.0-+11.4 \mathrm{~cm} \mathrm{H}_{2} \mathrm{O}$ with a mean of $+10.1 \mathrm{~cm} \mathrm{H}_{2} \mathrm{O}$. On expiration to FRC the volume displacements of
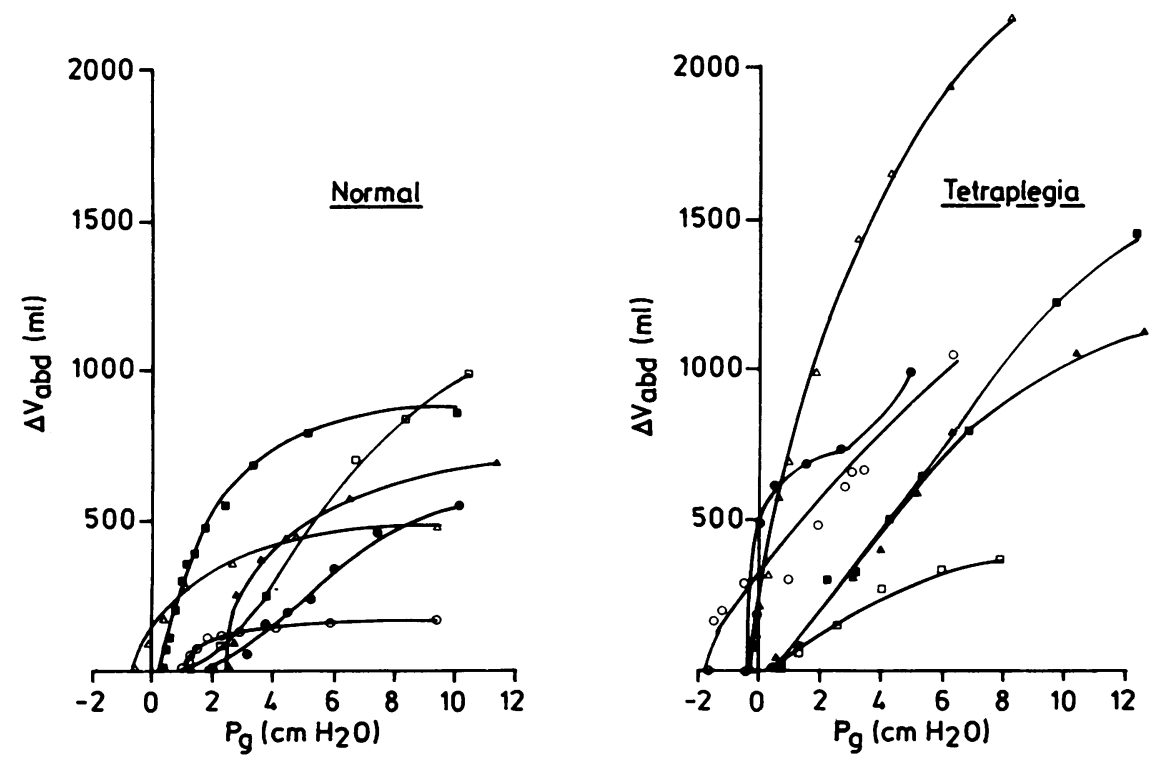

Fig 5 Gastric pressure/volume displacement characteristic of the abdominal wall: (a) six normal subjects; (b) six tetraplegic patients. $P_{\mathrm{g}}-$ gastric pressure; $\triangle V_{\mathrm{abd}}-v o l u m e$ displacement of the abdominal wall above that at functional residual capacity. 


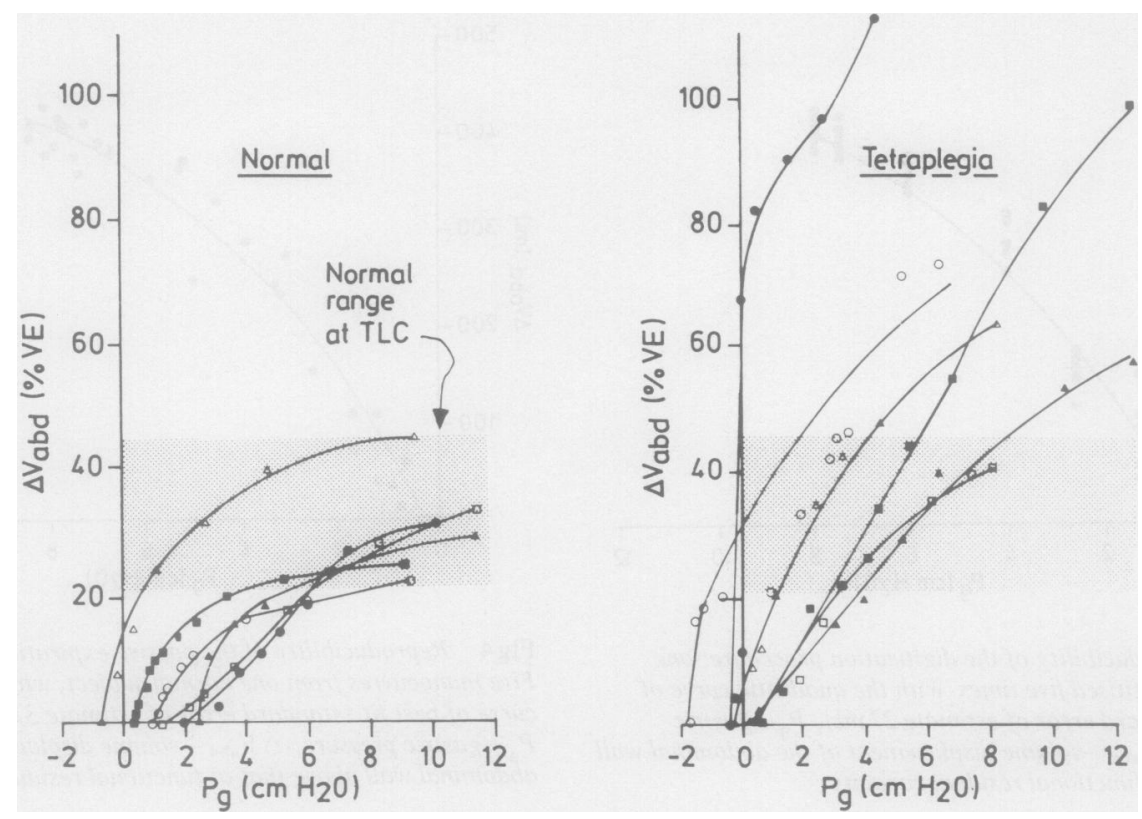

Fig 6 Gastric pressure/volume displacement characteristic of the abdominal wall: (a) six normal

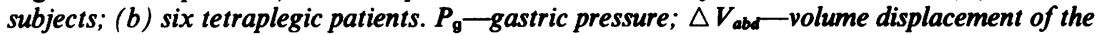
abdominal wall above that at functional residual capacity, expressed as a percentage of volume expired (\%VE).

the abdominal wall varied from 176 to $997 \mathrm{ml}$ with a mean of $624 \mathrm{ml}$. This range was due in part to differences in total expired volume. Figure $6 a$ shows abdominal wall displacement as a percentage of expired volume. In normal subjects the mean was $31 \%$ (SD $7.2 \%$ ) of total expired volume. The six patients with tetraplegia (Fig $5 a$ ) had a range of gastric pressure from -1.7 to $+12.5 \mathrm{~cm} \mathrm{H}_{2} \mathrm{O}$ during a relaxed expiration; their peak gastric pressure lay in the range $+5.0-+12.5 \mathrm{~cm}_{2} \mathrm{O}$ with a mean of $+8.7 \mathrm{~cm} \mathrm{H}_{2} \mathrm{O}$. This was less than in the normal subjects but the difference was not statistically significant. The tetraplegic patients had greater absolute volume displacements of the abdominal wall than the normal subjects $(413-2174 \mathrm{ml})$, with a mean of $1219 \mathrm{ml}$. When expressed in terms of percentage of expired volume (Fig $6 b$ ), the mean percentage volume partitioned to abdominal wall displacement was $77 \%$ (SD 34\%). These findings suggests that the anterolateral abdominal wall is displaced about twice as easily in tetraplegic patients - that is, it is twice as compliant as in normal subjects, even in the spastic phase of paralysis.

\section{Discussion}

The compliance of the abdominal wall is an import- ant factor in the interaction between the diaphragm and the rib cage. The posterior and inferior boundaries of the abdominal cavity are fixed by the spinal column and pelvic bowl respectively. When the diaphragm descends on inspiration the abdominal wall is displaced anterolaterally. ${ }^{7}$ The compliance of the abdominal wall will determine the intra- $\frac{\sigma}{\sigma}$ abdominal pressure rise. This is turn is believed to 3 inflate the lower rib cage by two mechanisms-firstly, $\delta$ by a direct outward push over the area of apposition of the diaphragm ${ }^{8}$ and, secondly, by opposing $ᄋ$ descent of the diaphragm as its costal fibres contract, so that it is forced to lift and thus spread the lower rib cage. ${ }^{9}$ Hence if the abdominal wall is stiff there will be greater inflation of the lower rib cage than if it is $\sigma$ floppy. ${ }^{10}$ This is particularly relevant in the tet- $N$ raplegic patient, in whom the diaphragm is the only important inspiratory muscle.

The measurement of abdominal wall compliance requires the apparent change in the volume enclosed by the abdominal wall to be related to change in pres- $\stackrel{\infty}{\rightarrow}$ sure within it. This is clearly different from the mea- 0 surement of lung compliance since, by definition, the abdominal cavity itself does not change in volume. Measurement of abdominal wall displacement presents difficulties. Konno and Mead ${ }^{11}$ first described thoracoabdominal motion by extrapolating 
from the measurement of displacement of single points on the chest and abdomen to calculate tidal volume. This method was refined by the use of magnetometers and has been successfully applied in the study of respiratory mechanics. ${ }^{1213}$ It measures change in one dimension only, and to derive change in volume requires careful calibration of the system with the use, for example, of the isovolume manoeuvre to define volume-motion coefficients. This assumes that the thoracoabdominal wall has two degrees of freedom of motion, ${ }^{14}$ which may not be the case in tetraplegia. Bergofsky ${ }^{1}$ measured abdominal wall displacement as volume, using a plethysmograph sealed at the lower margin of the rib cage. This did not take into account craniocaudal movement of the costal margin during respiration. We have applied an optical contour mapping technique to the problem, and consider it to have advantages. It is a non-invasive system and does not interfere with the variables being measured; thus it is well suited for use in tetraplegic patients, who may be physiologically unstable and therefore difficult to study. It will accurately reconstruct the thoracoabdominal wall in three dimensions and allows measurement of change in volume in absolute terms. We used gastric pressure as a conventional measure of intra-abdominal pressure in man, recognising, as Decramer et al ${ }^{15}$ have shown, that pressure varies in different positions in the abdomen.

Morgan et $\mathrm{l}^{6}$ have used optical contour mapping to partition volume between rib cage and abdomen during a vital capacity manoeuvre. They found that in normal subjects $60 \%$ of the vital capacity was partitioned to the abdominal compartment, in contrast to our figure over the inspiratory capacity of $31 \%$.The difference is probably due to the different manoeuvres performed: our subjects expired passively to functional residual capacity, while Morgan's subjects expired actively to residual volume, which results in contraction of the abdominal muscles and a decrease in apparent abdominal dimensions. Konno and $\mathrm{Mead}^{11}$ measured the static volume pressure characteristics of the abdomen in six normal subjects while they were erect and supine. They related the anteroposterior diameter of the abdomen to relaxed gastric pressure at different lung volumes. In the supine posture they found that gastric pressure at different volumes ranged from 0 to $10 \mathrm{~cm} \mathrm{H}_{2} \mathrm{O}$, which is similar to our own findings. They found "abdominal compliance" to be greatest at low lung volumes and then to decrease at total lung capacity. Our curves are of a similar shape. At active TLC they noted that $34 \%$ of vital capacity was partitioned to the abdominal compartment, which is in broad agreement with our figure of $31 \%$ of total volume expired. Bergofsky, ${ }^{1}$ using plethysmography, measured "abdominal compliance" in absolute terms in five tet- raplegic patients at low lung volume. His figures of $90-120 \mathrm{ml} / \mathrm{cm} \mathrm{H}_{2} \mathrm{O}$ are similar to our findings in four of the six patients. The pressure-volume curves in his study were plotted only for tidal volumes and within this range are similar to ours. Estenne et al, ${ }^{16}$ measuring chest wall compliance by a weighted spirometer technique,${ }^{17}$ derived rib cage and abdominal compliance from magnetometer recording from three normal subjects and four tetraplegic patients. Their results are not strictly comparable as they did not make direct measurements of abdominal wall compliance, but they agree with our findings that "abdominal compliance" is greater in tetraplegic patients.

We have also analysed the pressure-volume curves produced in this study over the range of tidal breathing. This range was defined by measuring the mean rise in gastric pressure over 10 consecutive quiet breaths in each subject. We found that in normal subjects the mean volume partitioned to abdominal displacement over a tidal breath was 314 (SE 76) ml, while among the tetraplegic patients it was 477 (SE 95) $\mathrm{ml}$. When the data are expressed as percentages of the total volume displaced by the chest wall during the relaxation manoeuvre, the normal subjects partitioned $16.5 \%$ (SE 3.5\%) of the total expired volume to abdominal wall displacement during tidal breathing, while tetraplegic patients partitioned $34 \%$ (SE $11 \%)$. Since the mean change in gastric pressure during quiet breathing was $2.4 \mathrm{~cm} \mathrm{H}_{2} \mathrm{O}$ in both groups, we conclude that over the tidal range the abdominal compliance is considerably increased in patients with tetraplegia.

In normal subjects we have found a decrease in abdominal wall compliance at high lung volumes. This may be due to stretching of the abdominal muscles, whose elasticity decreases as they lengthen, or to actual abdominal muscle contraction on active inspiration to TLC. ${ }^{18}$ The percentage of expired volume partioned to abdominal wall displacement in the tetraplegic patients varied from $41 \%$ to $110 \%$, which is much greater than in our normal subjects. Paradoxical movement of the rib cage on inspiration is responsible for the partitioning of proportionally greater volumes to the abdomen, ${ }^{2}$ even exceeding $100 \%$ of the volume expired. This is not, however, a constant feature in all such patients and there is considerable variability between individuals. ${ }^{19}$

In this study we have shown that the abdominal wall is more compliant in tetraplegic patients than in normal subjects. This confirms the clinical observation in such patients that the abdomen is easily distended on inspiration, even though other skeletal muscles are spastic. We suggest that, although the abdominal muscles may be subject to mass spasms, these are not a constant feature and disuse atrophy possibly causes an overall decrease in muscle tone. 
Skeletal muscle commonly atrophies in patients with chronic upper motor neurone lesions; but there are no published pathological data on the abdominal muscles.

In conclusion, we were able to measure abdominal wall compliance reproducibly by using an optical contour mapping technique. The abdominal wall of the tetraplegic patient appears to be more compliant than that of the normal subject. This implies that less intraabdominal pressure will be generated by descent of the diaphragm, which would impair expansion of the lower rib cage and might have a detrimental effect on the distribution of ventilation.

We wish to thank the clinical research committee of the Brompton hospital for funding and the staff and patients of the NSIC Stoke Mandeville hospital for their kind cooperation.

\section{References}

1 Bergofsky EH. Mechanism for respiratory insufficiency after cervical cord injury. Ann Intern Med 1964;61:435.

2 Mortola JP, Sant' Ambrogio G. Motion of the rib cage and abdomen in tetraplegic patients. Clin Sci Mol Med 1978;54:25-32.

3 Danon J, Druz WS, Goldberg NB, Sharp JT. Function of the isolated paced diaphragm and the cervical accessory muscles in $\mathrm{Cl}$ quadriplegics. Am Rev Respir Dis 1979;119:909-19.

4 Morgan MDL, Gourlay AR, Denison DM. An optical method of studying the shape and movement of the chest wall in recumbent patients. Thorax 1984;39:101-6.

5 Gourlay AR, Kaye G, Morgan MDL, Denison DM, Peacock AJ. Analysis of an optical mapping technique for lung function studies. Comput Biol Med 1984;14:47-58.

6 Morgan MDL, Gourlay AR, Silver JR, Williams SJ,
Denison DM. Contribution of the rib cage to breathing in tetraplegia. Thorax 1985;40:613-7.

7 Agostoni E, Mead J. Statics of the respiratory system. In: Fenn WO, Rahn H, eds. Handbook of physiology. Section 3: Respiration. Vol 1. Washington DC: American Physiological Society, 1964:387-409.

8 Mead J. Functional significance of the area of apposition of diaphragm to rib cage. Am Rev Respir Dis 1979;119:31-2.

9 De Troyer A, Sampson M, Sigrist S, Macklem PT Action of costal and crural parts of the diaphragm on the rib in dogs. J Appl Physiol 1982;53:30-9.

10 De Troyer A. Mechanical actions of the abdominal muscles. Bull Eur Physiopathol Respir 1983;19:575-81.

11 Konno K, Mead J. Static volume pressure characteristics of the rib cage and abdomen. J Appl Physiol 1968;24:544-8.

12 Grassino A, Goldman MD, Mead J, Sears TA. Mechanics of the human diaphragm during voluntary contraction: statics. J Appl Physiol 1978;44:829-39.

13 Druz WA, Sharp JT. Activity of the respiratory muscles in upright and recumbent humans. J Appl Physiol 1981;51:1552-61.

14 Konno K, Mead J. Measurement of the separate volume changes of rib cage ard abdomen during breathing. $J$ Appl Physiol 1967;22:407-22.

15 Decramer M, De Troyer A, Kelly S, Zocch L, Macklem PT. Regional differences in abdominal pressure swings in dogs. J Appl Physiol 1984;57:1682-7.

16 Estenne M, Heilporn A, Delhez L, Yernault J, De Troyer A. Chest wall stiffness in patients with chronic respiratory muscle weakness. Am Rev Respir Dis 1983;128:1002-7.

17 Cherniak RM, Brown E. A simple method for measuring total respiratory compliance: normal values for males. $J$ Appl Physiol 1965;20:87-91.

18 Campbell EJM. An electromyographic study of the role of abdominal muscles in breathing. $J$ Physiol 1952;117:223-33.

19 Morgan MDL, De Troyer A. The individuality of chest wall motion in tetraplegia. Bull Eur Physiopathol Respir 1984;20:547-52. 